Revista de Filosofía

Volumen 66, (2010) 45 - 61

\title{
AMÉRICA DESREALIZADA*
}

\author{
Hernán Neira \\ Universidad de Santiago de Chile \\ hernan.neira@usach.cl
}

\begin{abstract}
Resumen
La epistemología histórico-filosófica de la "visión de los vencidos" suponía la existencia de una verdad, complementaria a la del vencedor. Sin embargo, esa perspectiva conduce, sin proponérselo, a un debilitamiento de la idea de verdad en relación con el continente americano. Eso abre la puerta a la desrealización de éste, evolucionando hacia la idea de que América es un juego de lenguaje dentro de otros juegos de lenguaje, sin remitir a una realidad o a una verdad epistemológico-filosófica. El análisis de algunos aspectos de la obra de Miguel León Portilla, Peter Mason, Peter Sloterdijk y de la Jornada de Omagua de Dorado, escrita en 1561, sirven de apoyo para lo aquí planteado.
\end{abstract}

Palabras Clave: visión de los vencidos, discurso sobre America, filosofía de la historia, epistemología de la historia, desrealización de América.

\begin{abstract}
The historical-philosophical epistemology of the vision of the vanquished (visión de los vencidos) supposed the existence of a true, complementary to the defeated's one, in all discourse on America. Nevertheless, that perspective leads, unwillingly, to a weakening of the idea of truth in relation to the continent. This opens the path to its derealisation and leads to the idea that America is a speech game within another speech games, and does not address a reality or a philosophical-epistemological truth. Our statements are supported by analysis of some aspects of the work of Peter Sloterdijk and Peter Mason and of the Journey of Omagua y Dorado, written in 1561.
\end{abstract}

KEYwORDs: Vision of the vanquished, discourse on America, philosophy of history, epistemology of history, desrealisation of America.

Fruto parcial de la investigación La globalización como una filosofía de la historia: bases americanas, financiado por el Fondo Nacional de Investigación, Ciencia y Tecnología, Chile, bajo el número 1085080. 
$\overline{R M}$ Uno de los rasgos más notables del período epistemológico, filosófico y ético poscolonial ha sido el fenómeno consistente en la recuperación de la visión de los vencidos, la que, en términos generales, puede incluir la visión que grupos subordinados o débiles tuvieron de los procesos que ellos mismos vivieron en América. Ello se da en un contexto más amplio: por un lado, la modificación del estatuto de realidad del continente, es decir, el continente se desrealiza epistemológicamente; $y$, por otro, el debilitamiento del interés por los discursos centrados en la perspectiva del colonizador. Adoptar alguna de las visiones de los vencidos contribuye, ya sea a formarse un cuadro más completo de lo sucedido en el continente, ya sea a desestabilizar el dogmatismo de visiones anteriores, donde los vencedores, justamente por haber vencido, establecieron las interpretaciones de su propia victoria y de la derrota de los grupos dominados. Existen obras notables surgidas desde la perspectiva de la visión de los vencidos, cuya aportación a la historia americana y a la filosofía de la cultura y de la historia son ya indesmentibles, obras que han sido producidas dentro y fuera del continente americano ${ }^{1}$.

Para realizar un examen de la línea que lleva desde la visión de los vencidos hasta la desrealización del continente, expondremos cuatro casos. El primero es el de la visión de los vencidos. El segundo es de Peter Mason, quien analiza la escritura sobre América. El tercero, el de Peter Sloterdijk, y nos sirve de marco general de cómo la noción de realidad está constituida por la representación. Y el cuarto y último es un análisis reciente de la crónica titulada Jornada de Omagua y Dorado, que narra una rebelión o más bien una ficción filosófico-jurídica. Como se verá, en los cuatro casos encontramos que los autores no se centran en una supuesta realidad del continente, sino en la representación de él. Naturalmente, nuestro análisis no podría ser exahustivo, porque no hay una sola visión de los vencidos, ni una sola forma de desrealizar el continente, si bien los autores elegidos nos parecen de importancia singular.

\section{Debilitamiento metafísico por medio de la visión de los vencidos}

La escuela histórico-epistemológica que busca la visión de los vencidos surge a partir de la segunda guerra mundial en un contexto de descolonización polémico, aunque concordado por las grandes potencias y, en consecuencia, lleva todas las marcas políticas y epistemológicas de aquella época ${ }^{2}$. La descolonización implica

1 Entre las que destacan las de Nathan Wachtel y de sus discípulos, como las del historiador mexicano Miguel León Portilla, del historiador chileno Gabriel Salazar o del semiólogo francés Tzvetan Todorov y, en un sentido quizás algo distinto, la de Edward Saïd.

3 Esta línea de estudios se consolidó en América y en Europa durante la segunda mitad del siglo veinte o incluso a principios del siglo veintiuno, como se constata por la orientación 
distinguir la visión del colonizador de la del colonizado. La tarea del filósofo, del historiador o del antropólogo descolonizador o descolonizado consistiría, entonces, en alcanzar, escuchar y/o manifestar la visión del vencido, a fin de alcanzar un aspecto de la verdad que previamente no había quedado de manifiesto. "Un aspecto", porque el subentendido del proceso descolonizador de la segunda mitad del siglo XX es que la verdad es multifacética, según se deduce de los acuerdos políticos que otorgan autonomía a las antiguas colonias: las colonias tienen su verdad; las antiguas potencias colonizadoras, también, lo que permite descolonizar sin culpar o perseguir a los responsables del colonialismo. La noción de visión de los vencidos es inseparable del proceso de descolonización concordado, a veces bajo la presión de las armas, entre colonizados y colonizadores. Por ello, para alcanzar la verdad multifacética haría falta dejar de lado algunos prejuicios epistemológicos del colonizador o de los grupos de mayor poder social e intelectual o, incluso, sin abandonar esos prejuicios, simplemente prestar atención a la voz de los subgrupos, a nivel local o internacional, aún no suficientemente estudiados. Con todo, esta perspectiva supone que, tras las palabras, hay un trasfondo "real" que legitima la polémica, pues eso real solo se alcanzaría, en totalidad, complementando la perspectiva del colonizador y del colonizado. Por ello, las visiones de los vencidos, tanto como las del vencedor, poseen convicciones metafísicas relativas a la verdad y a la realidad, que suponen firme, aunque solo parcialmente expuesta por cada opción epistemológica.

La visión de los vencidos, en los estudios americanos, es una mezcla de filosofía realista y hermenéutica, de base empírica, que pretendía, también, hacer justicia, saldar una deuda y contribuir a la liberación nacional de los colonizados. Las visiones de los vencidos son condición y anticipo de la liberación: liberación de la opresión, opresión entre cuyos aspectos se encuentra la incorporación, por parte del vencido, de los criterios de interpretación del dominante, que tienden a menoscabar al dominado y a justificar la dominación. Con la destrucción de los sistemas hermenéuticos locales que trajo la conquista y después la ocupación republicana de tierras hasta entonces inaccesibles para el Estado, las visiones indígenas y sus portadores fueron perseguidos, discriminados o simplemente se extinguieron por ausencia de seguidores, sin que, en muchos casos, se pueda hablar ni de mestizaje ni de síntesis (Gruzinski 1991; Neira 2002). El patrimonio que la visión de los vencidos busca recuperar consiste es la visión perdida o exterminada; y la deuda que busca satisfacer consiste en elevar dicho patrimonio a la categoría de bien cultural de la nación o del mundo, y no solo de los vencidos. La visión de los vencidos se convierte, así, en un patrimonio de la humanidad. En efecto, en el período poscolonial, abierto al fin de la Segunda Guerra Mundial y cerrado con la invasión de Irak por Estados Unidos, se subentiende que las culturas indígenas deben ser valoradas tanto por lo que fueron como por enriquecer el patrimonio del mundo y de las naciones que las destruyeron. Este enriquecimiento

de cátedras y publicación de libros tanto en historia, antropología, filosofía y estudios americanos. En España ha sucedido un fenómeno semejante, pero en menor grado y más lentamente. 
del planeta requiere -en la perspectiva descolonizadora-, hacer uso de visiones que recojan la visión del vencido y la integren al patrimonio de la ciencia y de la cultura mundial. Desde el punto de los valores, la visión de los vencidos es una manifestación de fidelidad de escucha y proximidad ética por parte del estudioso hacia los males pasados y presentes de la comunidad estudiada. Esta proximidad sería una garantía de la verdad en la interpretación, sobre la base de un principio hermenéutico, según el cual, para alcanzar la verdad, se debe tener, además de la competencia científica, algún tipo de proximidad con lo estudiado, proximidad moral, emocional o política. Esta proximidad sería especialmente apta cuando no se trata de grupos subordinados pequeños, incluso personas, en cuyo caso la deuda y el saldo no son tanto responsabilidad de Estados, sino de grupos sociales y tendencias intelectuales dominantes ${ }^{3}$. Miguel León-Portilla, uno de los más destacados historiadores del mundo colonial, escribe lo siguiente:

"rara vez se piensa en la admiración e interés recíproco que debió despertar en los indios la llegada de quienes venían de un mundo igualmente desconocido. Porque, si es atractivo estudiar las diversas formas como concibieron los europeos a los que, por error, llamaron "indios", el problema inverso, que lleva a ahondar en el pensamiento indígena - tan lejano y tan cercano a nosotros- encierra igual, si no es que mayor interés. ¿Qué pensaron los hombres del Nuevo Mundo, en particular los mesoamericanos, nahuas, mayas y otros al ver llegar a sus costas y pueblos a los "descubridores y conquistadores"? ¿Cuáles fueron sus primeras actitudes? ¿Qué sentido dieron a su lucha? ¿Cómo valoraron su propia derrota? Es cierto que estas preguntas no podrán contestarse en todos los casos. Mas, por lo menos, habrá algunas respuestas, tratándose de las culturas indígenas que alcanzaron mayor desarrollo. Sus textos y pinturas por una parte, y las relaciones españolas por otra, constituirán las dos caras distintas del espejo histórico en el que se refleja la Conquista"4.

La visión de los vencidos confirma, sin cuestionarlo, el supuesto de que las interpretaciones remiten a una verdad, del colonizado o del oprimido, pero verdad, aunque tenga dos aspectos. Como dice León Portilla: "dos caras distintas del espejo histórico en el que se refleja la Conquista", una conquista que opera como soporte metafísico de las distintas visiones.

Sin embargo, al mismo tiempo que remiten a esta verdad, estas visiones la presentan como alcanzable solo por perspectivas, realistas, por cierto, como si fueran

3 El principio de proximidad entre el estudioso y lo estudiado, como condición para acceder a esto último, se manifiesta en corrientes tan diversas como en aquella cristiana, según la cual para conocer se requiere proximidad con la carne de Cristo, o como en la noción de empatía (Einfühlung) en Dilthey o del interés de clase en el marxismo.

4 Versión on line de León-Portilla, Miguel editor. Crónicas indígenas, Visión de los vencidos. Ed. Historia 16, Madrid 1985. http://www.biblioweb.dgsca.unam.mx/libros/vencidos/intro.html. 28/10/08. 
un "espejo" en un ángulo que se define por la opción epistemológica propia de cada pueblo. Pero, aunque León Portilla no se lo haya propuesto (sigue apegado a un realismo decimonónico), ya el hecho de que cada pueblo tenga una opción epistemológica contribuye al debilitamiento de la verdad metafísica relativa al continente americano y a la Conquista. De hecho, una metodología nunca es solo una metodología y todo asunto epistemológico es, además, un asunto metafísico, porque contribuye a constituir o a diluir la realidad y a darle ciertas características.

El debilitamiento de la solidez metafísica del continente no se debe a una inhabilidad de quienes han tomado la perspectiva de la visión de los vencidos, sino a un hecho que tiene múltiples orígenes. Políticamente, se inicia con la descolonización; filosóficamente, con la idea de que dos epistemologías (la del vencedor y la del vencido) pueden conducir a un resultado idéntico en cuanto a su categoría de verdad, pero distinto en cuanto a su contenido. Al poner el énfasis en la visión de los vencidos, es imposible desconocer el hecho de que se trata, justamente, de una visión y, por lo tanto, de que la historiografía hace uso de una representación, no solo de una constatación.

La recuperación de las visiones subordinadas contribuye, por cierto, a ampliar el conocimiento y a alcanzar una verdad más integral e integradora de América, pero al precio de debilitar la noción misma de verdad y de hacerla descender de su pedestal metafísico. ¿Por qué? Porque muestra que incluso la mejor de las epistemologías conduce solo a un aspecto de la verdad. En otras palabras, incluso la antiguamente admirada epistemología del vencedor solo conduce a la limitada verdad de éste, a su verdad. A partir de allí, el vencido se verá tentado, por el legítimo ánimo de liberación que lo mueve, a pensar que la verdad del vencedor es, en el fondo, mirada positivamente, solo una semi verdad y, mirado negativamente, una semi falsedad o, en casos aún más graves, una simple falsedad. El vencedor puede oponer idénticos argumentos al vencido y calificarlo de promover una falsedad y así reprocharse, recíprocamente, la incapacidad científica, como de hecho ha comenzado a suceder a medida que la historia se balcaniza y disminuye el interés por una historia global. Es un camino sin salida: la oposición entre la visión del vencido y del vencedor no conduce tanto al triunfo de cualquiera de los miembros de la oposición, como a abandonar una disyuntiva que tiene por base, y por problema, la existencia de la noción de verdad, cuya contraparte necesaria es la falsedad, pues ambas necesitan de su contrario para sostenerse.

Es que la superación de las visiones contrapuestas, incluso reducidas al nivel epistemológicamente disminuido de visión, obliga a colocarse en un plano distinto de aquel en que cada una de ellas se sitúa (el duro sentido metafísico del realismo) para desplazarse hacia la epistemología de la representación. El enriquecimiento de las visiones sobre continente americano que trajo consigo la epistemología de la visión de los vencidos desplaza la epistemología sobre el continente hacia la idea de que no hay ni una ni muchas verdades, sino tan solo imágenes, visiones, pero sin buscar en ellas el apoyo en una realidad. Por ello, ya a fines del siglo XX y más aun a principios del XXI, algunos investigadores han tendido a centrarse en la representación del continente y no en aquello a lo que dichas representaciones se supone remiten. De esta forma, se constata una tendencia, entre algunos historiadores, antropólogos y filósofos a la "desrealización" del continente americano. Esta desrealización consiste 
en abandonar la metafísica de la verdad/falsedad, lo que supone abandonar la tarea de interpretar signos o documentos en relación con aquello a lo que remitirían para, en el futuro, centrarse en las imágenes como principio y fin de la investigación y, sobre todo, del continente. América se identifica, entonces, con sus imágenes, y éstas con el continente, sin pretender ir más allá de ello. Dicho en términos de Ferdinand de Saussure, algunos americanistas contemporáneos abandonan la división entre significado y significante para quedarse únicamente con el último. Como consecuencia de lo anterior, se abandona también la búsqueda de una o varias verdades de América, en todas los aspectos que pueda tomar la verdad: espejo o representación de algo real, adecuación o copia de las ideas a ello, exposición de una idea o realización en un territorio, fenómeno que, además de tener lugar en la filosofía y la historia, ha tenido un amplio desarrollo en algunos artistas visuales ${ }^{5}$. Es necesario ver quiénes y cómo han realizado, en las últimas décadas, esta labor de desrealización preparada epistemológicamente por la visión de los vencidos.

2. Tres modos de desrealizar: globalización, archiescritura y subescritura filosófica

El primer momento en la desrealización de América está constituido por la obra En el espacio interior del capitalismo. Por una teoría filosófica de la globalización (Sloterdijk 2005), Peter Sloterdijk sostiene que intenta recapitular la historia de la globalización terrestre y se plantea proponer, "con los medios de un gran relato filosóficamente inspirado, el contorno para una gran teoría del presente" (Sloterdijk 2005, p. 11). En el mismo texto, Sloterdijk cita a Heidegger, coincidiendo con lo que afirma éste en Die Zeit des Weltbildes: que el fundamento móvil del nuevo tiempo es el descubrimiento del mundo como imagen, pero no como una imagen del mundo, sino el mundo como imagen (Sloterdijk 2005, p. 153). Este nuevo tiempo es el de los grandes viajes del siglo XVI, llamados de "descubrimiento" (Entdeckungsfahrt), solo que este descubrimiento también habría sido una ocultación. Descubrir y ocultar no son dos cosas distintas, sino aspectos del mismo fenómeno de constitución del mundo como imagen. La idea de que el descubrir es un ocultar hace un guiño a las filosofías de la sospecha, es decir, a la de Marx, Nietzsche y Freud, quienes, desde distintas perspectivas, analizan la oscilación entre ocultamiento y desocultamiento y aquello

5 Muchos de ellos, además, lo han hecho con sentido crítico y como una exploración de las relaciones entre América y otras regiones del mundo, otrora dominantes, como es el caso de Juan Dávila, Karen Pazán y otros.

6 "Indem [man] die Geschichte der terrestrischen Globalisierung rekapituliert, nimmt sich vor, mit den Mitteln einer philosophisch inspirierten großen Erzählung Umrisse zu einer Theorie der Gegenwart zu liefern" (Sloterdijk, p. 11). 
que da lugar a dicha oscilación ${ }^{7}$. La filosofía de la sospecha parte del supuesto de que hay una apariencia, pero una apariencia que se define en relación con una realidad o fundamento oculto, aunque sospechable, desde la apariencia. Sloterdijk acoge dicha tradición, pero va más allá, pues ya no acepta que exista una realidad o un fundamento oculto tras la apariencia. Para Sloterdijk, en tanto sigue a Heidegger en este punto, la "realidad" del mundo sería la imagen del mundo. De esta forma, ya no sería posible separar, por un lado, la realidad del mundo y, por otro, la representación de dicha realidad. A partir de esa situación, es posible concebir, pero solo concebir y no constatar, que haya una realidad tras la imagen. La imaginación puede crear la imagen de lo "real", pero no transformarla en un concepto con contenido, porque lo real, como tal, no es alcanzable por algún tipo de intuición. En esta perspectiva, una afirmación sobre un más allá de lo representado en una representación del mundo puede ser solo una hipótesis.

Esta es la línea seguida en En el espacio interior del capital... Peter Sloterdijk sostiene allí que la representación de la Tierra como esfera no antecede la globalización, sino que es parte de ella. En efecto, globalización y representación de la tierra no son separables ni lo podrían ser, porque la representación de los fenómenos, en tanto producto o constitutivo de un mundo globalizado, son la globalización. La globalización es una determinada forma de representarse el mundo, representación que se constituye, según Sloterdijk, en tres principios (Anfänge). Usa esta palabra y no etapa (Stufe, Abschnitt, etc.), porque no se trata de una secuencia temporal, a pesar de su aspecto histórico, sino de lo que en filosofía se llama un principio, es decir, un fundamento o una forma que se despliega, está presente y hace posible el conocimiento. En cada uno de estos tres principios hay una nueva forma de representación, coherente con la anterior, pero distinta, y que globaliza aspectos que en los principios precedentes no estaban contemplados.

El primer principio de la globalización descrito por Sloterdijk sería griego. Para los griegos, representarse la esfera (Kugel) terrestre como portadora y contenedora de vida reflexiva habría sido constitutivo del universo. "La cosmología de la antigüedad occidental, esto es, la platónica y la erudición de la helenística posterior, había descrito la idea de representar la totalidad de lo existente en la estimulante imagen de una esfera omniabarcante (Sloterdijk 2005, p. 19) ${ }^{8}$. El segundo principio residiría en la racionalización de la estructura del mundo a través de los cosmólogos antiguos que, por primera vez, se representaron la totalidad de lo existente en figuras esféricas. "La ontología clásica era una doctrina del mundo tanto como una doctrina divina es una

7 Coincide, además, con algunas afirmaciones de Tzvetan Todorov en La conquête de l'Amérique, la question de l'autre.

8 "Die Kosmologie des westlichen Altertums, namentlich die platonische und die der späteren hellenistischen Gelehrten, hatte sich der Idee verschrieben, das Ganze des Seienden in dem stimulierenden Bild einer allumfassenden Sphäre darzustellen" (Sloterdijk 2005, p. 19). 
esferología" (Sloterdijk 2005, p. 19) ${ }^{9}$. Ambos principios parecen similares, pero no lo son. El primero es un contenedor de la vida y un constitutivo del universo; el segundo, en cambio, se representa al universo entero como esférico. Por último, el tercer momento de la globalización se realizaría mediante los viajes crístico-capitalistas, que se implantan mediante el colonialismo de las naciones europeas a partir del siglo XVI. El núcleo de ello sucede entre 1492 y 1945, pero en la actualidad el sistema mundial (Weltsystem) sigue sus mismos contornos (Sloterdijk 2005, p. 21). Dos de los tres principios descritos por Sloterdijk corresponden a formas de representar el mundo, no a hechos. El tercero, en cambio, busca proveer una experiencia de la esfericidad del mundo y hacerla concordante con dicha imagen, lo que se realiza mediante una política de globalización que consiste en viajes, circulación mundial de mercancías y transmisión del Evangelio ${ }^{10}$.

Coherentemente con lo planteado por Sloterdijk, la forma esférica que contiene la vida en el cosmos (es decir, la Tierra) y, después, los viajes que efectúan la globalización, no son antecedentes o fundamento de la globalización, sino que la globalización se realiza en esos principios, los cuales son ya globalización y, quizás, el paso más importante en su realización. Esto separa a Sloterdijk de otros teóricos, para quienes la globalización es un vínculo material (vías de comunicación, comercio, cultura global, etc.), donde el pensamiento sobre ella sería, más bien, una suerte de reflexión a posteriori y externa al fenómeno mismo. Para Sloterdijk, no se trata tampoco

"Die klassische Ontologie war als Weltlehre wie als Gotteslehre eine Sphärologie" (Sloterdijk 2005, p. 19).

10 Sloterdikj no conoce el pensamiento de Vitoria quien, sin embargo, hubiera podido aportarle buenos argumentos respecto del sentido de sus tesis sobre los viajes crístico-capitalistas. En efecto, Vitoria promueve la libertad de la circulación de bienes, de ideas (especialmente religiosas) y de personas. Que los indios vivan en comunidades soberanas no implica que no haya causas legítimas para hacerles la guerra. Si una nación cualquiera, indígena o europea, interviene contra el orden natural u ofende a un Estado, éste está obligado por el derecho natural a defenderse a fin de defender a los miembros de su comunidad. En efecto, al atacarse u ofenderse a un Estado, se está atacando al medio mediante el cual los humanos cumplen con el llevar recíprocamente las cargas de la existencia. Entre las ofensas al Estado o a sus miembros, Vitoria incluye los ataques a la vida (los sacrificios humanos, etc.), las restricciones a la libertad de evangelización, de circulación y de comercio, todas las cuales se deducirían del derecho natural. Que tales libertades estén inscritas en el derecho natural se debe a que todos los hombres tienen derecho a "beneficiarse" del Evangelio, así como tienen derecho a ir donde les plazca y comerciar para contribuir con bienes producidos por otros al deber de llevar de manera compartida las cargas de la existencia. Interesa, pues, a la república universal, que todas las sociedades puedan beneficiarse del saber y productos de todas las sociedades en un mundo considerado patrimonio común. Si alguna de estas libertades fuese violada o restringida por los indios o por cualquier otro pueblo, la guerra sería legítima. Pero incluso en situación de guerra la ley natural sigue vigente. El pueblo vencedor puede y debe, después de haber sido indemnizado y haber restablecido el orden de la república universal, respetar las instituciones y gobierno que los vencidos se den entonces (Vitoria 1969). 
de la influencia que el pensamiento sobre ciertos hechos puede tener sobre éstos, sino que el hecho mismo de la globalización tiene, como componente esencial, el pensarse en una esfera, lo que se daría muy tempranamente.

Es comprensible, entonces, que ya antes de los cada vez más audaces viajes del siglo XV y XVI se haya concebido y existido la globalización y que podamos insertarla en una historia que también se inicia mucho antes de las transformaciones que dan lugar a la llamada época moderna o incluso posmoderna ${ }^{11}$. Ahora bien, conviene insistir y aclarar que no todo vínculo es globalización. Para que un vínculo sea globalización o globalizante debe ir acompañado del hecho epistemológico de representar el universo o la Tierra bajo la forma esférica. Mucho antes de los tiempos pitagóricos hubo vínculos entre pueblos de Asia y Europa; entre los de Escandinavia y del Mar Negro; y entre los de Norteamérica y Sudamérica, pero esos hechos no constituyen o no habrían constituido globalización, porque dichos vínculos entre pueblos no iban acompañados de la conciencia y de la epistemología del mundo como esfera. Siguiendo a Sloterdijk, este pensamiento, indispensable para concebir la globalización, comienza con el pensar el mundo como una esfera, en la antigua Grecia, siguiendo un modelo pitagórico de perfección, y culmina en la actualidad, cuando la relación entre lo extranjero y lo próximo (Ansässigen) se da en un espacio homogéneo, constituido por un discurso. No se trata, por tanto, de una globalización entendida como expansión territorial (aunque pueda incluirla), sino como una filosofía, como una filosofía de la historia y un discurso sobre la historia. El espacio de la globalización es, ante todo, un discurso. Sloterdijk define por globalización "la forma epistemológica de la aventura que gesticula ante la verdad como un sirviente. Expresado programáticamente, el primado del viaje de ida, el viaje a lo lejos, es puesto como expedición [...] la globalización no es un caso de expansión espacial; sino que pertenece al núcleo de la historia de la verdad en los nuevos tiempos" (Sloterdijk 2005, p. 152) ) $^{12}$.

La recién citada oración de Sloterdijk es un poco ambigua, pues la globalización o es una forma epistemológica o es el núcleo de la historia. En tanto forma epistemológica, la globalización no puede ser un contenido, y es lo que hace posible pensar cualquier contenido, lo que no se presenta como condición, ni como fundamento, sino como núcleo de la historia de la verdad. Mientras que la forma epistemológica tiene que ver con la condición de representación de la historia, el núcleo de la historia está en el ámbito de los hechos. La globalización, en consecuencia, es la forma de la

11 Fines de la Segunda Guerra Mundial, en el plano social, y tal vez antes, en el plano filosófico.

12 "epistemologische Form des Abenteuertums, das sich wie ein Dienst and der Wahrheit gebärdet [gesticula]. Wird der Primat der Hinfahrt programmatisch ausgesprochen, so stellen sich die Fernreisen als Expeditionen vor [...] Die Expedition ist die Routinenform des unternehmensartig angesetzten Suchen und Findens. Ihretwegen [por eso] ist die entscheidende Bewegung der realen Globalisierung nicht einfach ein Fall von räumlicher Expansion; sie gehört zum Kernprozeß der neuzeitlichen Wahrheitsgeschichte" (Sloterdijk 2005, 152). Nosotros tradujimos. 
historia de Occidente y la forma como Occidente entiende la historia. Ahora bien, la globalización, en términos de Sloterdijk, es, a la vez, núcleo histórico y forma epistemológica.

Ahora bien, la globalización, en términos de Sloterdijk, es núcleo histórico y forma epistemológica. La globalización sería, entonces, una constante o, más aun, el núcleo estable que hace comprensible y da unidad a la historia y, con ello, la hace posible. En otras palabras, el núcleo de la narración de la historia es una globalización que no es histórica ni tampoco un hecho perteneciente al campo de lo real, sino condición de la representación de la historia y de la realidad global. La hipótesis sloterdijkiana es que la globalización es lo que hace posible que hoy tengamos lo que llamamos "historia" y que ésta sea global, en lugar de una suma de hechos separados.

Así puede entenderse, entonces, la afirmación de Sloterdijk según la cual el discurso sobre la globalización no es solo un discurso relativo a los hechos, sino un relato sobre la evolución de la humanidad y sobre la expansión de la verdad o, más bien, de un tipo de verdad en el mundo. La globalización sería "el único período de la vida en el cual los pueblos que se descubren uno al otro, alias la 'humanidad', merecen, en un sentido filosóficamente relevante, llamarse 'historia' o 'historia 'mundial'. La historia mundial era el surgimiento de la Tierra como portadora de la cultura y del éxtasis; su orientación era el egoísmo triunfante de las naciones europeas en expansión; su estilo lógico es la adquisición indiferente de todas las cosas"13 (Sloterdijk 2005, p. 28). La globalización es una forma que apunta a abarcar todo y que, debido a su éxito, concibe lo indiferente y lejano como perteneciente a una unidad y a un sujeto, que es la humanidad y, sobre todo, la humanidad occidental. La ciencia histórica, en consecuencia, es deudora de la globalización, del mismo modo que lo sería todo relato de los pueblos en el tiempo y todo relato del conocimiento y del vínculo entre éstos. Pensar o representarse que pueda existir una historia "universal" y una unidad de la especie humana es ya practicar la globalización.

Un segundo momento, en la desrealización contemporánea de América, tiene lugar en la obra Deconstructing America, Representations of the Other (Mason 1990). Allí, Peter Mason realiza una interpretación de la construcción de América como fruto de imágenes que se originan en la antigüedad greco-romana y que son trasladadas a la descripción de América a partir de 1492. Una de las tesis fundamentales del libro, fuertemente influenciado por la Gramatología de Jacques Derrida, es que América no corresponde a una realidad. Por ello, lo que se entiende por América sería el fruto

13 "das einzige Zeitstück im Leben der sich gegenseitig [uno al otro] entdeckenden Völker alias "Menschheit", das es verdient, in einem philosophisch relevanten Sinn "Geschichte"oder "Weltgeschichte" zu heißen. Die Weltgeschichte war die Herausarbeitung der Erde als Trägerin der Kulturen und der Ekstasen; ihr politischer Duktus war die triumphierende Einseitigkeit der expsansiven europäischen Nationen; ihr logischer Stil ist die indifferente Auffassung aller Dinge" (Sloterdijk 2005, p. 28). Nosotros tradujimos al castellano. 
de la construcción de un texto y no fruto de la observación de una realidad, de la que no se sabe nada, pues la "realidad" de América no sería algo distinto del texto que la constituye y narra.

Según Mason, el nombre América funciona dentro de un sistema de clasificación, sin un contenido propio, tal como proponen Lévi-Strauss y Derrida. Por ello, carece de un valor vocativo absoluto: "puesto que ellas [las palabras], no apuntan de hecho hacia algo, el significado surge no en la supuesta diferencia entre palabras y objetos mismos a los que se referiría, sino en la diferencia entre las mismas palabras" (Mason 1990, p. 33) ${ }^{14}$. Para entender la relación entre, por un lado, el sistema de clasificación y las palabras, y, por otro, éstas y el objeto que nombran, conviene recordar que, en un sistema de clasificación, tal como lo entiende Lévi-Strauss, los signos clasificados (palabras, por ejemplo), solo significan en relación con los significados contiguos, que también son palabras. El sistema de clasificación, de este modo, no remite a una realidad clasificada, sino a un sistema de significados cuyo sentido solo puede alcanzarse al tener una visión de conjunto de él o, al menos, de la estructura que permite diferenciar los significados por medio de significantes.

Más adelante, Mason, apoyándose en Foucault y en la hipótesis de que el discurso de ficción tiene efectos de verdad, sostiene que el contenido de un concepto como América no es reducible a la ideología colonial. En efecto, si América fuera solo el fruto de una "ideología", bastaría con descifrar lo que la ideología encubre para dar con la realidad del continente, aun cuando dicha realidad sea el colonialismo. Las filosofías de la "sospecha", que afirman la existencia de una falsa representación, oponen dicha falsedad a una representación verdadera, a la que se llega cuando desvela la ideología que la oculta. Pero Mason se aleja de dicha postura y se plantea, no en términos de las filosofía de la sospecha o de las filosofía crítica, sino de la deconstrucción: "América parece emerger, a partir de nuestro análisis, de una carencia. Como nombre propio, carece de una referencia concreta; como efecto de lo real, se presenta a sí mismo como una carencia a un estilo que está seguro de su habilidad para penetrar la verdad" (Mason 1990, p. 34) ${ }^{15}$.

Mason continúa explicando cómo la Historia naturalis de Plinio el Viejo (hacia el siglo I a. d. C.) y su descripción de las razas humanas llega a la Edad Media y se encuentra en la biblioteca de Colón. Mason sostiene que, por ejemplo, las razas de Plinio se manifiestan en la Historia de las Indias de Nueva España, del dominico Diego Durán, terminado en 1581. Supuestamente, al dominico, los indios le narran retratos de hombres con un solo ojo. ¿Habría, pues, tradiciones de razas monstruosas en

14 "since they [las palabras] do not in fact just point at something, meaning arises not in the supposed difference between words and the objects to which they would refer, but in the difference between words themselves" (Mason 1990, p. 33).

15 “' America' seems to emerge from our analysis as a lack. As a proper name, it lacks a concrete referent; as a effect of the real, it presents itself as a lack to a style which is assured of its ability to penetrate the truth" (Mason 1990, p. 34). 
América antes de la llegada de los españoles? ¿O bien las razas monstruosas, tal como las concibe Plinio, forman parte de la estructura clasificatoria del monje español? Luis de Santangel, en 1493, describe algunas amazonas, a pesar de que no comprende el idioma indígena porque falta el intérprete. En la Historia naturalis de Plinio el Viejo son descritos hombres que tienen dieta de pájaros, con cara de caballo, etc. En el siglo XIV, Mandeville describe pueblos de localización nunca definida, con cabeza de perro, lo que posteriormente contribuye a proveer una imagen negativa de algunos indios americanos, como se verá en parte de la iconografía europea sobre América. Para Mason, las razas de Plinio funcionan como un lenguaje y, la articulación corporal que describe (con cara de caballo, etc.), es una articulación lingüística. "Las razas de Plinio no serían ni un lenguaje de dominación ni de rebelión [...] Más que un lenguaje, son una Babel, subvirtiendo el discurso que trata de imponer a la variedad de pueblos una unidad de estructura (Mason 1990, p. 91). La Babel de las razas de Plinio, a diferencia de la estructura jerárquica colonial, carece de jerarquía y no se ordena con un centro y periferia. Esas descripciones de Plinio influyen en las de Colón y en otras posteriores relativas al cuerpo de los indios. Si extraemos las consecuencias que es necesario extraer, las descripciones del cuerpo de los habitantes del Nuevo Mundo son parte de la descripción del texto llamado América. Colón pone en duda el relato, pero trata de adaptar lo que escucha y supone que las islas están habitadas por el Gran Khan (Mason 2005, p. 103). Colón se inspiraría, pues, en una tradición que va desde lo descrito por Pausanias en las islas Satyr, donde se supone que los habitantes tienen cola y violan mujeres (Mason 2005, pp. 103-104), hasta Plinio el Viejo.

La base filosófica de esta afirmación se encuentra en la noción de archiescritura, elaborada por Jacques Derrida. Mason la define en los siguientes términos: "La archiescritura es la forma pura del concepto de escritura previa a su realización en una sustancia significante. Precede al habla y a la escritura dado que precede la misma división de regiones de la sensibilidad. Hace imposible todo tipo de jerarquía entre el registro acústico y el fenómeno visual o el registro gráfico" (Mason 2005, p. 146) ${ }^{16}$. La pintura corporal de los indios, al igual que la atribución a ellos de ciertos comportamientos por Colón, son una forma de escritura, no porque se compare con la ideográfica o fonética, sino porque, si se está de acuerdo con la hipótesis derridiana, los indios dispondrían de una capacidad de lenguaje que hace posible todo lenguaje, incluyendo el corporal, base que es la misma para todo lenguaje y que, en consecuencia, no permite establecer jerarquías entre uno pictórico y otro oral o escrito. El cuerpo pintado forma parte de un código que, junto con otros cuerpos también pintados, constituye un sistema de comunicación complejo. La misma archiescritura que hace posible el lenguaje de la pintura corporal dirige (commande) todo discurso (pintado,

16 This archi-écriture is the pure form of the concept of writing prior to its realisation in a signifyinig substance. It precedes speech and writing since it precedes the very division of the regions of sensibility. It makes impossible any kind of hierarchy between the registration of acoustic phenomena and visual or graphic records" (Mason 1990, p. 146). 
escrito, oral, etc.) y toda objetividad. En consecuencia, la archiescritura también hace posible todo discurso y objetividad sobre América ${ }^{17}$.

Desde esta perspectiva derridiana, donde el referente metafísico desaparece para ser sustituido por la explicación de cómo trabaja la metafísica, Mason intenta realizar algo semejante en relación con América. América ya no representa aquí un "otro" o un "referente" de ese nombre, sino que es el conjunto de representaciones. En Deconstructing America, Mason analiza cómo "trabaja" el sistema lingüístico que hace posible la constitución progresiva del concepto América. Ahora bien, el autor británico no extrae las consecuencias epistemológicas que podrían deducirse de su trabajo y se limita a afirmar que la palabra América es integrante de un juego de lenguaje en el cual el significado es el mismo juego de lenguaje. Es decir, Mason esboza, pero no desarrolla las consecuencias globales que él mismo deduce y que llevarían a una desrealización del continente americano, no solo de sus descripciones. Si se es plenamente consecuente con la noción de archiescritura, en la que se apoya, se llega a una des-metafisicación general del concepto de América, es decir, no solo al análisis de cómo trabaja el juego de lenguaje llamado "América", sino a una hipótesis de carácter filosófico. Esta hipótesis consiste en que América pierde su "contenido", en que deja de ser una "realidad" y pasa a ser una representación y clasificación, cuyo contenido es el conjunto de representaciones del continente, las cuales, a su vez, carecen de contenido, pues remiten a otros juegos lingüísticos.

El tercer momento en la desrealización del continente americano puede reflejarse en un texto más antiguo, como es la Jornada de Omagua y Dorado, de 1561. En efecto, el análisis de Deconstructing America podría sugerir que la des-metafisicazación del continente es solo un procedimiento posmoderno, una especie de isla en medio de la historia y de la representación del continente. Sin embargo, no es así. La Jornada narra, al menos en un nivel, la rebelión y derrota de Lope de Aguirre, quien se "desvasalló" de Felipe II y a quien ofreció "la más cruda guerra que nuestras fuerzas puedan sustentar" (Vázquez 1986, p. 117), todo ello mientras se encontraba en Venezuela, tras haber recorrido el Amazonas en una balsa y haber asesinado al gobernador Pedro de Ursúa en 1559. Ahora bien, la detallada crónica escrita por los soldados Francisco Álvarez y Pedrarias de Almesto, tiene dos particularidades. La primera es que se trata de una crónica, género a la vez científico, jurídico y literario, y que tiene por finalidad dar cuenta de "hechos" y de hacerlo de una manera realista. La segunda peculiaridad es que los hechos de armas que describe la Jornada siguen una estructura narrativa que es la de la teoría filosófica de la sumisión a un señor por parte una asamblea o de un grupo humano que vive libremente, la ruptura de dicho pacto y la restauración del orden. La teoría, llamada del "pacto de sumisión”, es una ficción

17 El estudio del funcionamiento de la lengua supone que se ponga entre paréntesis la sustancia del sentido, pues la lengua es una forma, no una sustancia, como dice Saussure. La archi-escritura es movimiento de la diferencia, que abre en una sola posibilidad la temporalización, la relación a otro y el lenguaje (Mason 1990, 88). 
filosófico-jurídica que permitió explicar la legitimidad del poder político desde los comienzos del feudalismo hasta el fin de absolutismo. Ahora bien, cabe preguntarse si los soldados autores de la crónica "están describiendo los hechos de un viaje o solo precisamente montando piezas en una narración filosófica para crear el significado de "lealtad" y de "el motín de Lope de Aguirre"" (Neira 2006). Es que la Jornada narra una estructura filosófica en dos planos. El primero es el de un motín. En el otro, los autores crean la figura del amotinado y del culpable, tal como podía ser entendida por la filosofía política del siglo XVI y por la Audiencia de Santo Domingo hacia 1561, lo que supone narrar, más que hechos, una historia filosófico-jurídica que crea jurídicamente ciertos hechos. El "realismo" del género "crónica de indias" no solo describe hechos, sino la epoya crístico-colonizadora de los conquistadores en América y la derrota de sus enemigos, aunque sean españoles. A ello se agrega, en el caso de la Jornada, que sus autores son dos soldados que quieren exculparse del crimen de lesa majestad por el que deben responder ante la Audiencia. De acuerdo con ello, la Jornada es la representación de una ficción filosófica creada para orientar una decisión jurídica, lo que solo es posible por la separación previa de las palabras con respecto de un motín realizado por Lope. Esto no significa que sea un relato de ficción, sino que es una crónica, con todas las características que ello implica, lo que no impide, sin embargo, que la crónica sea, así como toda descripción realista, una construcción filosófico-jurídica, un juego de lenguaje, el del apego a los hechos.

El aspecto performativo de la Jornada no se puede reducir a la exculpación de sus autores ante la Andiencia. Su performatividad se realiza de forma similar a como actúan las imágenes de Plinio en algunas narraciones sobre América: aquellas imágenes predefinen la apariencia visual con que los indios son vistos por algunos europeos y crean el sistema, el marco y hasta contribuyen a constituir el contenido visual de lo que se observará. La estructura filosófico jurídica del pacto de sumisión es el marco desde el cual, con el cual y teñido por el cual los soldados narran los acontecimientos relativos a Lope de Aguirre. A fin de explicar la ruptura hecha por Lope contra la Corona o, más bien, de crearla narrativamente, la estructura filosófico-jurídica del pacto de sumisión, eje del derecho político feudal, prefigura el relato de los soldados y establece el lugar, orden y contenido de los hechos que van a ser narrados. Lo que los autores de la Jornada no podían prever, claro, era que la intensidad con que crean en Lope la figura del amotinado, figura a la que la teoría del pacto de sumisión da su fuerza, iba a darle al soldado rebelde una fama y un valor simbólico central en la historia y en la conciencia de América (Pastor 1983).

\section{América desrealizada: conclusión}

El debilitamiento del valor y de los supuestos metafísicos de la verdad tiene consecuencias generales en la filosofía, en los estudios americanos, en la creación cultural y en relaciones políticas entre las naciones. Abandonar la polémica verdad/falsedad relativa a América significa, también, el abandono de la filosofía de la historia que coloca a América en una línea posterior a Europa, temporal y jerárquicamente en 
la búsqueda de dicha verdad y en el desarrollo del pensamiento racional. Esa historia, que fue la historia crístico-feudal en transición hacia una historia crístico-capitalista y que después fue la historia de la Ilustración, supone un desarrollo progresivo de la verdad, que habita preferentemente en los países y razas donde se llevó a cabo con mayor celeridad una forma de historia, que fue la de la racionalización general de la sociedad bajo la creencia de que allí radicaba el progreso. Esa historia, narrada por Condorcet, por Hegel y por Marx, aunque cada uno lo haga de distinto modo, define la realidad de América como un lugar de expansión natural de cierto tipo de verdad. Lo define, pero no lo nombra, porque ninguno de dichos autores la considera suficientemente relevante por estar alejada de lo que consideran el progreso y la verdad. Al abandonar esa historia de la verdad, la palabra América deja de remitir a una realidad, en gran medida conformada por los criterios europeos de racionalización del mundo y de las imágenes del mundo, criterios incorporados como propios en el mundo americano. El abandono de la polémica verdad/falsedad efectúa, además, una liberación, muchas veces crítica, de las imágenes y de la imaginación americana, de gran repercusión en el tratamiento estético de los héroes y antihéroes. Esas imágenes y esa liberación de imágenes son parte de la América actual, América desrealizada.

Esta nueva tendencia filosófica e histórica no es un giro o moda posmodernos, ni a una confabulación político-intelectual, sino que es fruto del desarrollo y de la continuación lógica del trabajo de descolonización intelectual surgido después de la Segunda Guerra Mundial, trabajo que, necesariamente, evoluciona. Sin embargo, como hemos visto, hay rasgos de desrealización incluso en crónicas que, durante largo tiempo, fueron consideradas constatación de una verdad y de una realidad, como es el caso de la Jornada de Omagua y Dorado. En esta evolución intelectual y cultural, los estudios americanos pueden tomar aspectos contradictorios, aunque no falsos, pues es necesario recordar a Hegel, cuando, en el Prólogo de la Fenomenología del espíritu, explica que lo verdadero y lo falso, vistos en su desarrollo histórico, no se oponen, sino que se siguen y requieren uno a otro, pues uno surge del interior del otro. Es dentro de ese marco y dentro de esta historia del pensamiento sobre América que podemos y debemos situar la tendencia de algunos autores de hoy, que centran su trabajo en la representación en lugar de buscar cuál sea la o las verdades sobre América.

El concepto llamado América no es solo un objeto geográfico, sino que se inserta en un discurso y es un discurso, entendido como escritura y archiescritura. Éste trata de la historia de la humanidad, se representa la historia de la humanidad y es la historia de la humanidad en tanto la historia es representación. Esta representación tiene a la globalización como forma de la verdad, globalización que debe ser entendida como forma y no contenido. Sloterdijk dice que la globalización es forma de la verdad, manteniendo una ambigüedad, en el sentido de que no se sabe si, en definitiva, abandona o no la noción metafísica de verdad, como parecen indicarlo algunos párrafos de En el espacio interior del capitalismo. Creemos, sin embargo, que dicha ambigüedad debe ser despejada en la ya mencionada orientación que opta por la imagen y la representación.

La evolución del concepto de América y de los estudios americanos ha transitado por tres etapas. La primera es de la convicción en una verdad única provista 
por España u otros países de Europa, detentada por los colonizadores y sus herederos. La segunda corresponde a una verdad entendida como opción epistemológica, como perspectiva, como visión y, en especial, como visión de los vencidos. Por último, a pesar de su variedad, uno de los rasgos principales de la etapa actual es la desrealización del continente americano, desrealización en curso, aunque, como corresponde a todo proceso histórico, jamás será realizada por completo. La desrealización ha sido posible porque, desde el mismo siglo XVI, la noción de América es partícipe de una de las principales corrientes de discurso sobre la humanidad: la humanidad comienza a ser concebida en relación (de oposición, comparación o concordancia) con las narraciones sobre los indios americanos. La epistemología de la visión de los vencidos, sin habérselo planteado, generó parte del clima en que la teoría de la deconstrucción de Derrida podía asentarse. A esta conclusión puede llegarse gracias a la evolución de los estudios americanos, sin los cuales difícilmente se puede comprender la historia y menos hacer una filosofía de la historia capaz de entender al ser humano de hoy, porque ni en Europa ni en ningún lugar del planeta son ya los tiempos en que se pueda elaborar una filosofía de la historia desatendiendo la historia de América, historia cuyo proceso es arquetipo de globalización y colonización.

\section{Bibliografía}

Derrida, Jacques (1997), De la grammatologie. Paris: Editions du Minuit, coll. Critique.

Foucault, Michel (2003), Surveiller et punir. Naissance de la prison. Paris: Gallimard, colléction TEL.

Gruzinski, Serge (1991), La colonización de lo imaginario, Sociedades indígenas y occidentalización en el México español. Siglos XVI-XVlll. México: Fondo de Cultura Económica.

Hegel, George Wilhem Friedrich (1954), Phänomenologie des Geistes. Hamburgo: Felix Meiner Verlag.

León-Portilla, Miguel editor. Crónicas indígenas, Visión de los vencidos. Ed. Historia 16, Madrid 1985. http://www.biblioweb.dgsca.unam.mx/libros/vencidos/ intro.html. 28/10/08.

Mason, Peter (1990), Representations of the Other. London: Routledge.

Neira, Hernán (1990), La idea de origen en el concepto de América. Revista Araucaria de Chile, $\mathrm{N}^{\mathrm{o}}$ 47-48. (Puede consultarse en: www.neira.cl/IdeadeOrigenConceptoAmerica90.PDF).

(2002), "Mestizaje y canibalismo", en Rebeca León, ed., Arte en América Latina y cultura global. Santiago: Dolmen Ediciones.

Neira, Hernán et al. (2006), "Lope de Aguirre: elementos para la teoría del mito de la Conquista". Estudios Filológicos (Valdivia) 41: 145-163. 
Pastor, Beatriz (1983), Discurso narrativo de la conquista de América. La Habana: Ediciones Casa de las Américas.

Posse, Abel (1981), Daimon. Barcelona: Argos Vergara.

Sloterdijk, Peter (2005), Im Weltinnenraum des Kapitals, Für eine philosophische Theorie der Globalisierung. Frankfurt: Suhrkamp. Erste Auflage.

Todorov, Tzvetan (sin fecha), La conquête de l'Amérique, la question de l'autre. Paris: Ed. du Seuil.

Vázquez, Francisco, y Pedrarias de Almesto (1986), Jornada de Omagua y Dorado; Crónica de Lope de Aguirre. Madrid: Miraguano Ediciones, colección Los Malos Tiempos.

Vitoria, Francisco de (1969), De los Indios. De la potestad civil, en Obras de Francisco de Vitoria. Madrid: Biblioteca de Autores Cristianos. 